\section{A) Check for updates}

Cite this: Dalton Trans., 2021, 50 2483

Received 15th December 2020, Accepted 8th January 2021

DOI: $10.1039 / \mathrm{d} 0 \mathrm{dt} 04261 \mathrm{~g}$ rsc.li/dalton

\title{
A chromatography-free total synthesis of a ferrocene-containing dendrimer exhibiting the property of recognizing 9,10-diphenylanthracene $\uparrow$
}

\begin{abstract}
Artur Kasprzak, (D) *a Monika K. Nisiewicz ${ }^{\mathrm{a}, \mathrm{b}}$ and Anna M. Nowicka (D) ${ }^{\mathrm{b}}$
Molecules comprising several ferrocene residues constitute an intriguing group of compounds for various applications. Here, the total synthesis of a new example of a ferrocene-containing dendrimer is presented. The target compound was obtained in excellent combined yield $(65 \%)$ employing facile, chromatography-free methods at each step. Interesting findings, meeting the dynamic covalent chemistry concept, are reported. Cyclic voltammetry analyses revealed one pair of current signals for the ferrocene moieties. Ultimately, the synthesized ferrocene-containing dendrimer has been used as an innovative recognition material for 9,10-diphenylanthracene, a polycyclic aromatic hydrocarbon, with the limit of detection value equal to $0.06 \mu \mathrm{M}$.
\end{abstract}

\section{Introduction}

Over the years, ferrocene $(\mathrm{Fc})$ has been a coordination compound of wide interest in organic and materials chemistry. ${ }^{1,2}$ This metallocene has various prospective applications in a number of important fields, such as medicinal chemistry, ${ }^{3}$ self-healing materials, ${ }^{4}$ catalysis $^{5}$, or ion receptors. ${ }^{6}$ Even though the discovery of $\mathrm{Fc}$ was accomplished 80 years ago, in recent years its chemistry has developed remarkably, and Fccontaining molecules have become important synthetic targets.

The synthesis of compounds bearing several $\mathrm{Fc}$ residues has been one of the major goals of modern chemistry, since such molecules exhibit intriguing chemical structures, as well as unprecedented properties and applications. Some of the milestones achieved in recent years include, e.g. the reports by Albrecht \& Long on the preparation of a Fc cyclic oligomer ${ }^{7}$ or Fc-bearing macrocycles. ${ }^{8}$ Special interest has been given to the synthesis of Fc-containing dendrimers. Dendrimers have advantages in comparison to their linear or branched macromolecular analogs, such as well-defined monodispersed structures, encouraging bio-physical features and the possibility of the control of the position and number of introduced substituents. ${ }^{1,9,10}$ These beneficial parameters of dendrimers are extremely important also from the viewpoint of their

\footnotetext{
${ }^{a}$ Department Faculty of Chemistry, Warsaw University of Technology, Noakowskiego Str. 3, 00-664 Warsaw, Poland. E-mail: akasprzak@ch.pw.edu.pl

${ }^{b}$ Faculty of Chemistry, University of Warsaw, Pasteura Str. 1, 02-093 Warsaw, Poland $\dagger$ Electronic supplementary information (ESI) available: Compound characterization data and spectra. See DOI: 10.1039/d0dt04261g
}

applied sciences, e.g., medicinal chemistry or organic electronics. The literature reports on Fc-containing dendrimers include the preparation of silicon- ${ }^{11-13}$ tetraphenylmethane- ${ }^{14 a}$ pyridylphenylene- ${ }^{14 b}$ or $\quad$ poly(amidoamine)-based ${ }^{15,16 a}$ structures as well as metallodendrimers, ${ }^{16 b}$ hydrogenbonded, ${ }^{16 c}$ or coordination-type ${ }^{16 d-f}$ assemblies. These dendrimers showed interesting features, such as water solubility, ${ }^{17}$ catalytic activity, ${ }^{13}$ ion recognition ${ }^{14 b, 16 c}$ or the property to form inclusion complexes with cyclodextrins. ${ }^{15}$ The chemistry of metallocene-tethered dendrimers has intensively developed over the years, and a number of these interesting molecules have been summarized in recent reviews. ${ }^{18 a-e}$

Importantly, the dendrimer chemistry has been commonly merged with the $\pi$-conjugation concept, since $\pi$-conjugated aromatic compounds bearing a number of delocalized $\pi$-electrons were reported as interesting frameworks and ideal materials for various applications. ${ }^{18 f-h, 19 a}$ In general, the analysis of the literature examples of Fc-containing dendrimers brings a conclusion that the previous reports focused mostly on the installation of ferrocene units in the peripheral parts of the $\pi$-conjugated dendrimer cores. The reports dealing with aromatic dendrimers with $\mathrm{Fc}$ units located both in the peripheries and the core are sparse, as well as the synthesis of these molecules is challenging; in consequence there is limited number of reports on the successful synthesis of such organized compounds (see the graphical representation in Fig. 1). Even though the examples of such dendrimers can be found in the literature, one may conclude that the synthetic protocols are time-, cost- and solvent-consuming, such as in the case of the interesting phosphorous-containing ferrocene-tethered dendrimers. ${ }^{19 b, c}$ 


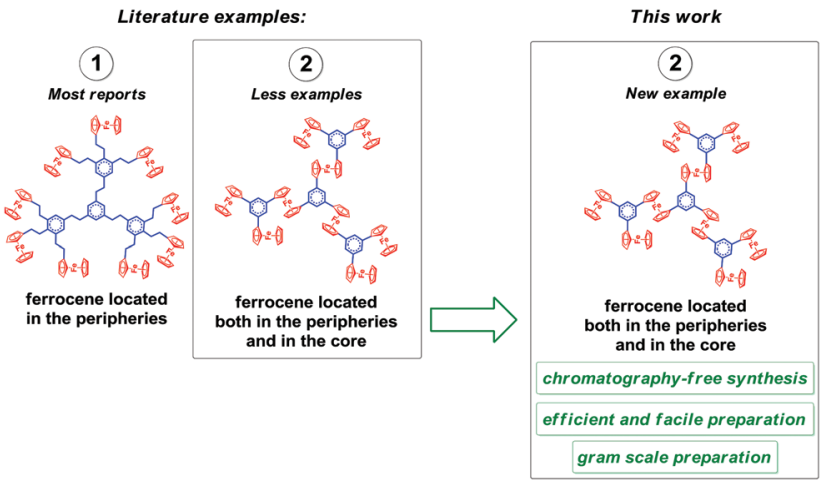

Fig. 1 Graphical summary of the reported Fc-decorated dendrimers and the aim of this work.

In pursuit of new dendrimers consisting of several Fc units and $\pi$-conjugated building blocks, herein a chromatographyfree total synthesis of the novel Fc-containing dendrimer Fcden is presented (Fig. 2). Our goal was to design a new, chromatography-free and efficient way for the synthesis of a Fc-tethered dendrimer of potential interest to various communities. The structure of Fc-den includes 1,3,5-triphenylbenzene cores and imine linkages. These structural motifs have been widely employed for the construction of organized $\pi$-conjugated molecules, including several examples of aromatic dendrimers with Fc units located in the peripheries of the dendrimer. ${ }^{5,20,21 a, b}$ We expect $\pi$-conjugation within a Fc-den framework because of enhancing the number of delocalized p-electrons of the 1,3,5- triphenylbenzene framework (bearing multiple bonds) with imine linkages (bearing $\mathrm{C}\left(\mathrm{sp}^{2}\right)$ and $\mathrm{N}\left(\mathrm{sp}^{2}\right)$ atoms) and cyclopentadienyl rings bound on the opposite sides of the iron atom (Fc units of Fc-den).

The herein presented synthesis of Fc-den bearing nine Fc residues lies in a convergent synthesis strategy, in which the key to success was the preparation of two $\pi$-conjugated building blocks 1 and 2 (Fig. 2). In general, we hypothesized that sequential imine-bond formation reactions shall provide the target dendrimer and intermediate compounds. Importantly, the success of this strategy would be also beneficial in terms of the green synthesis of Fc-den, since the previous studies on imine-containing triphenylbenzenes ${ }^{5,21,22}$ suggested that no chromatographic purification shall be required.

\section{Experimental section}

\section{Materials and methods}

Chemical reagents and solvents were commercially purchased and purified according to the standard methods, if necessary. NMR experiments were carried out using a Varian VNMRS $500 \mathrm{MHz}$ spectrometer $\left({ }^{1} \mathrm{H}\right.$ NMR at $500 \mathrm{MHz}$ or ${ }^{13} \mathrm{C}$ NMR at $125 \mathrm{MHz}$ ) equipped with a multinuclear $z$-gradient inverse probe head. Unless otherwise stated, the spectra were recorded at $25{ }^{\circ} \mathrm{C}$. Standard $5 \mathrm{~mm}$ NMR tubes were used. ${ }^{1} \mathrm{H}$ and ${ }^{13} \mathrm{C}$ chemical shifts $(\delta)$ were reported in parts per million (ppm) relative to the solvent signal: $\mathrm{CDCl}_{3}, \delta_{\mathrm{H}}$ (residual $\mathrm{CHCl}_{3}$ ) $7.26 \mathrm{ppm}, \delta_{\mathrm{C}} 77.2 \mathrm{ppm}$. NMR spectra were analyzed with the

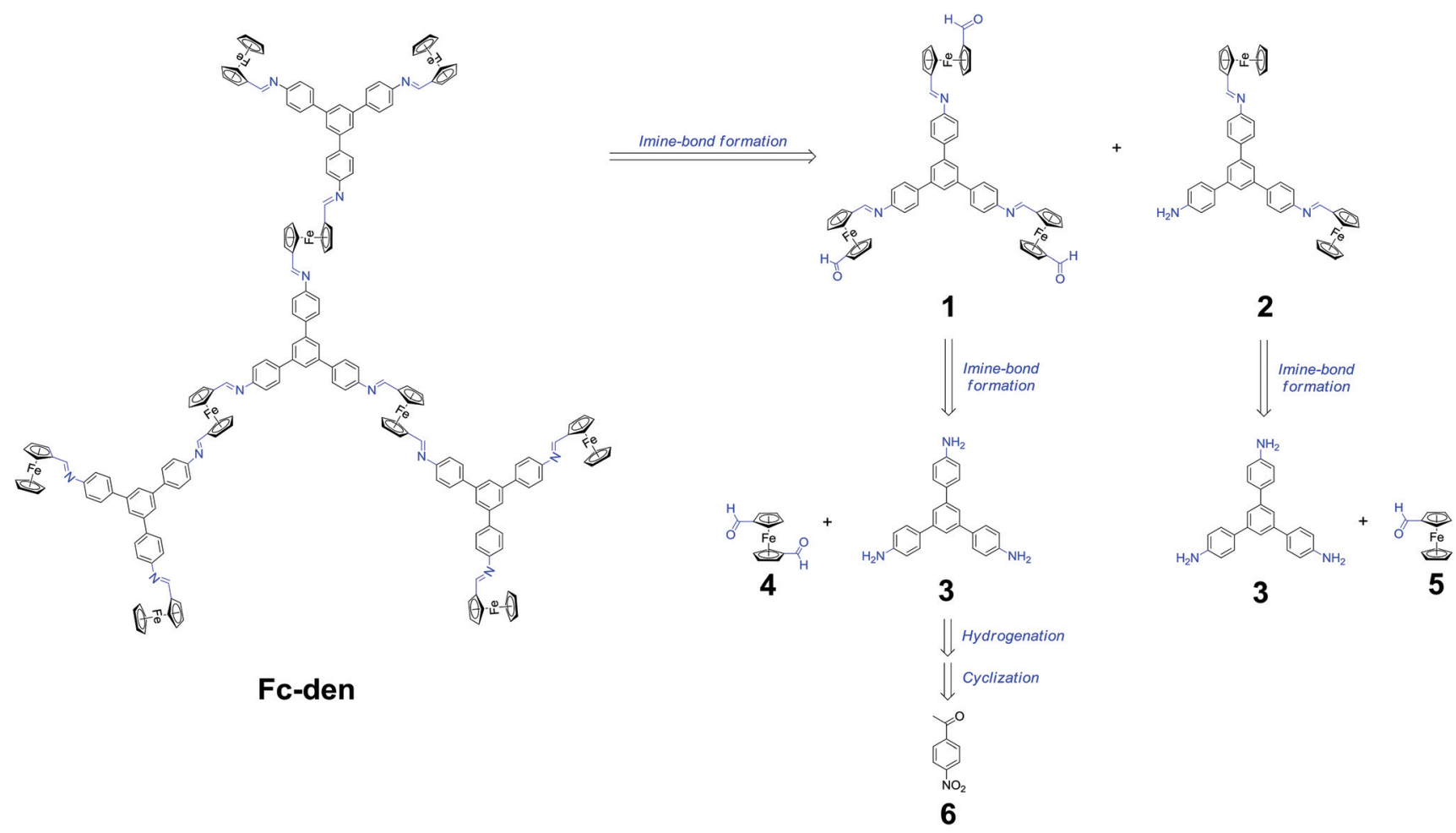

Fig. 2 Structure of the target Fc-containing dendrimer (Fc-den) and its retrosynthetic analysis. 
MestReNova v12.0 software (Mestrelab Research S.L). ${ }^{1} \mathrm{H}$ DOSY (Diffusion Ordered SpectroscopY) NMR experiments were performed using a stimulated echo sequence incorporating bipolar gradient pulses and with convection compensation. The gradient strength was logarithmically incremented in 15 steps from $25 \%$ up to $95 \%$ of the maximum gradient strength. The DOSY Toolbox software was used for DOSY NMR spectral processing (The DOSY Toolbox - version 2.5, 2014, Mathias Nilsson, School of Chemistry, University of Manchester, UK).

Fourier-transform infrared (FT-IR) spectra were recorded in the attenuated total reflectance (ATR) mode with a Thermo Nicolet Avatar 370 spectrometer with a spectral resolution of $2 \mathrm{~cm}^{-1}$ (100 scans). The wavenumbers for the absorption bands $\nu$ were reported in $\mathrm{cm}^{-1}$.

UV-vis measurements were performed with the PerkinElmer spectrometer Lambda 25, at room temperature in a quartz cuvette with a $1 \mathrm{~cm}$ long optical window. For the UV-Vis measurements, the wavelengths for the absorption maxima $\lambda_{\text {max }}$ were reported in $\mathrm{nm}$.

TOF-HRMS (ESI) measurements were performed with a Q-Exactive ThermoScientific spectrometer. Melting points were determined on Standford Research Systems MPA 100 and were uncorrected.

Elemental analyses were performed using CHNS Elementar Vario EL III apparatus. Each elemental composition was reported as an average of two analyses.

Electrochemical measurements were performed using an Autolab Eco Chemie potentiostat, model PGSTAT 12 controlled via software on a personal computer. All experiments were carried out in a three-electrode system. A disc glassy carbon electrode (GC, $\varnothing=3 \mathrm{~mm}$, BAS Instruments) was used as the working electrode, an $\mathrm{Ag} / \mathrm{AgCl} / 3 \mathrm{M} \mathrm{KCl}$ as the reference electrode, and a platinum wire as the auxiliary electrode. Before each experiment, the GC electrode was polished with $1 \mu \mathrm{m}$ aluminium oxide powder on a wet pad, rinsed with water and then dried with argon. During all measurements, the electrochemical cell was kept in a Faraday cage to minimize the electrical noise. The measurements were carried out with deoxygenated solutions.

\section{Synthesis of 1}

To a stirred solution of 1,3,5-tris(4-aminophenyl)benzene (3) (140.6 mg, $0.40 \mathrm{mmol}, 1.0$ equiv.) and 9,10-diphenylantracene (528.6 mg, $1.60 \mathrm{mmol}, 4.0$ equiv.) in $\mathrm{MeOH}(15 \mathrm{~mL})$, a solution of 1,1'-diformylferrocene (4) (871.4 mg, $3.60 \mathrm{mmol}, 9.0$ equiv.) in $\mathrm{MeOH}(13 \mathrm{~mL})$ was added in one portion. Glacial acetic acid $(250 \mu \mathrm{L})$ was added, and the mixture turned turbid within several minutes. The reaction mixture was stirred at room temperature for 24 hours. The solid was filtered off and washed with methanol $(15 \mathrm{~mL})$. The solid residue was suspended in methanol $(80 \mathrm{~mL})$, sonicated for 20 minutes at room temperature, filtered off, washed with methanol $(10 \mathrm{~mL})$ and dried at room temperature for 24 hours to give compound 1 (393.1 $\mathrm{mg} ; 96 \%$ yield) as an orange-red solid.

Mp: $262-263{ }^{\circ} \mathrm{C} ;{ }^{1} \mathrm{H}$ NMR $\left(\mathrm{CDCl}_{3}, 500 \mathrm{MHz}, \mathrm{ppm}\right), \delta_{\mathrm{H}} 9.95$ $(\mathrm{s}, 3 \mathrm{H}), 8.13$ (s, 3H), 7.41 (s, 3H), 7.24-7.22 (m, 6H), 6.82-6.81 (m, 6H), 4.96-4.88 (m, 12H), 4.58-4.52 (m, 12H); ${ }^{13} \mathrm{C}\left\{{ }^{1} \mathrm{H}\right\}$ NMR $\left(\mathrm{CDCl}_{3}, 125 \mathrm{MHz}, \mathrm{ppm}\right), \delta_{\mathrm{C}} 193.0$ (3C), 160.6 (3C), 141.3 (3C), 138.2 (3C), 127.5 (3C), 123.8 (3C), 121.4 (3C), 120.6 (6C), 84.7 (3C), 82.4 (3C), 72.6 (6C), 71.4 (6C), 70.5 (6C), 70.1 (6C); FT-IR (ATR), $v$ 3082, 3014, 2868, 2830, 1682, 1614, 1588, 1508, 1364, 1242, 1178, 1038, 820, $744 \mathrm{~cm}^{-1}$; UV-Vis, $\lambda_{\max }\left(\mathrm{CHCl}_{3}\right) 264$, $333 \mathrm{~nm}$; TOF-HRMS (ESI): calcd for $\mathrm{C}_{60} \mathrm{H}_{46} \mathrm{Fe}_{3} \mathrm{~N}_{3} \mathrm{O}_{3}[\mathrm{M}+\mathrm{H}]^{+}=$ 1024.1582, found: $\mathrm{m} / \mathrm{z}$ 1024.1561; Anal. calcd for $\mathrm{C}_{60} \mathrm{H}_{45} \mathrm{Fe}_{3} \mathrm{~N}_{3} \mathrm{O}_{3}$ : C, 70.41; $\mathrm{H}, 4.43 ; \mathrm{N}, 5.65$. Found: C, 70.50; H, $4.44 ; \mathrm{N}, 4.10$.

\section{Synthesis of 2}

A solution of 3 (1054.2 mg, $3.00 \mathrm{mmol}, 1.0$ equiv.) and ferrocenecarboxaldehyde (5) (1605.3 $\mathrm{mg}, 7.50 \mathrm{mmol}, 2.5$ equiv.) in $\mathrm{MeOH}(300 \mathrm{~mL})$ was stirred for 5 minutes. Glacial acetic acid $(1800 \mu \mathrm{L})$ was added, and the mixture turned turbid within several minutes. The reaction mixture was stirred at room temperature for 24 hours. The solid was filtered off and washed with methanol $(15 \mathrm{~mL})$. The solid residue was suspended in methanol $(200 \mathrm{~mL})$, sonicated for 20 minutes at room temperature, filtered off, washed with methanol $(10 \mathrm{~mL})$ and dried at room temperature for 24 hours to give compound 2 (2052.0 $\mathrm{mg} ; 92 \%$ yield) as an orange solid.

Mp: $225-226{ }^{\circ} \mathrm{C} ;{ }^{1} \mathrm{H}$ NMR $\left(\mathrm{CDCl}_{3}, 500 \mathrm{MHz}, \mathrm{ppm}\right), \delta_{\mathrm{H}} 8.44$ $(\mathrm{s}, 2 \mathrm{H}), 7.82(\mathrm{~s}, 3 \mathrm{H}), 7.75-7.71(\mathrm{~m}, 6 \mathrm{H}), 7.31-7.28(\mathrm{~m}, 4 \mathrm{H})$, 6.82-6.79 (m, 2H), 4.86 (bs, 2H), 4.80-4.79 (m, 4H), 4.61-4.60 $(\mathrm{m}, 4 \mathrm{H}), 4.28(\mathrm{~s}, 10 \mathrm{H}) ;{ }^{13} \mathrm{C}\left\{{ }^{1} \mathrm{H}\right\} \mathrm{NMR}\left(\mathrm{CDCl}_{3}, 125 \mathrm{MHz}, \mathrm{ppm}\right)$, $\delta_{\mathrm{C}} 161.5$ (2C), 146.0 (2C), 142.3 (1C), 142.1 (1C), 132.1 (2C), 128.4 (4C), 128.2 (2C), 123.4 (2C), 123.1 (2C), 121.2 (2C), 115.6 (4C), 115.5 (2C), 73.4 (2C), 71.6 (4C), 69.8 (10C), 69.5 (4C); FT-IR (ATR), $v$ 3080, 3026, 2890, 1634, 1579, 1496, 1160, 1096, 954, 800, $740 \mathrm{~cm}^{-1}$; UV-Vis, $\lambda_{\max }\left(\mathrm{CHCl}_{3}\right)$ 269, $340 \mathrm{~nm}$; TOF-HRMS (ESI): calcd for $\mathrm{C}_{46} \mathrm{H}_{38} \mathrm{Fe}_{2} \mathrm{~N}_{3}[\mathrm{M}+\mathrm{H}]^{+}=744.1759$, found: $m / z$ 744.1760; Anal. calcd for $\mathrm{C}_{46} \mathrm{H}_{37} \mathrm{Fe}_{2} \mathrm{~N}_{3}$ : C, 74.31; $\mathrm{H}$, 5.02; N, 5.65. Found: C, 74.62; H, 5.00; N, 5.67.

\section{Synthesis of Fc-den}

A solution of 1 (460.6 mg, $0.45 \mathrm{mmol}, 1.0$ equiv.) and 2 (1107.9 mg, $1.49 \mathrm{mmol}, 3.3$ equiv.) in THF: MeOH 1:1 v/v $(80 \mathrm{~mL})$ was stirred for 5 minutes. Glacial acetic acid $(300 \mu \mathrm{L})$ was added, and the mixture turned turbid within several minutes. The reaction mixture was stirred at room temperature for 48 hours. The solid was filtered off and washed with THF : MeOH $1: 1 \mathrm{v} / \mathrm{v}(10 \mathrm{~mL})$. The solid residue was suspended in THF : MeOH $1: 1 \mathrm{v} / \mathrm{v}(100 \mathrm{~mL})$, sonicated for 20 minutes at room temperature, filtered off, washed with THF:MeOH 1:1 $\mathrm{v} / \mathrm{v}(10 \mathrm{~mL})$ and dried at room temperature for 24 hours to give Fc-den (1281.6 mg; 89\% yield) as a red solid.

Mp: $>300{ }^{\circ} \mathrm{C} ;{ }^{1} \mathrm{H}$ NMR $\left(\mathrm{CDCl}_{3}, 500 \mathrm{MHz}, \mathrm{ppm}\right), \delta_{\mathrm{H}} 8.45(\mathrm{~s}$, $6 \mathrm{H}), 8.14(\mathrm{~s}, 6 \mathrm{H}), 7.80(\mathrm{~s}, 9 \mathrm{H}), 7.75-7.71(\mathrm{~m}, 18 \mathrm{H}), 7.41(\mathrm{~s}, 3 \mathrm{H})$, 7.31-7.29 (m, 18H), 7.24-7.21 (m, 6H), 6.82-6.79 (m, 6H), 5.10-5.09 (m, 12H), 4.85-4.84 (m, 12H), 4.53-4.52 (m, 24H), $4.28(\mathrm{~s}, 30 \mathrm{H}) ;{ }^{13} \mathrm{C}\left\{{ }^{1} \mathrm{H}\right\} \mathrm{NMR}\left(\mathrm{CDCl}_{3}, 125 \mathrm{MHz}, \mathrm{ppm}\right), \delta_{\mathrm{C}} 161.6$ (6C), 161.5 (6C), 152.4 (3C), 151.2 (3C), 146.2 (3C), 146.1 (3C), 142.1 (3C), 141.3 (3C), 138.5 (6C), 138.3 (6C), 138.2 (6C), 131.9 (3C), 128.3 (6C), 128.4 (6C), 128.2 (6C), 128.1 (6C), 124.6 (3C), 
124.2 (3C), 123.9 (3C), 123.7 (3C), 121.4 (6C), 121.3 (3C), 115.6 (6C), 115.5 (6C), 82.4 (6C), 80.6 (6C), 73.3 (6C), 71.6 (6C), 71.5 (12C), 70.0 (6C), 69.8 (6C), 69.5 (30C), 69.3 (12C); ${ }^{1} \mathrm{H}$ DOSY NMR (500 MHz, $\left.\mathrm{CDCl}_{3}, 0.7 \mathrm{mM}\right), D 0.901 \times 10^{-10}$; FT-IR (ATR), $v$ 3086, 3024, 2884, 1620, 1584, 1490, 1456, 1168, 1102, 954, 818, $746 \mathrm{~cm}^{-1}$; UV-Vis, $\lambda_{\max }\left(\mathrm{CHCl}_{3}\right)$ 284, 295, 363, $492 \mathrm{~nm}$; TOF-HRMS (ESI): calcd for $\mathrm{C}_{198} \mathrm{H}_{151} \mathrm{Fe}_{9} \mathrm{~N}_{12}[\mathrm{M}+\mathrm{H}]^{+}=$ 3200.6318, found: $\mathrm{m} / \mathrm{z}$ 3200.6330; Anal. calcd for $\mathrm{C}_{198} \mathrm{H}_{150} \mathrm{Fe}_{9} \mathrm{~N}_{12}$ : C, 74.32; H, 4.72; N, 5.25. Found: C, 74.40; H, $4.74 ; \mathrm{N}, 5.26$.

\section{Results and discussion}

The synthetic studies were initiated by synthesizing 1,3,5-(4aminophenyl)triphenylbenzene (3; Fig. 3a) in two steps following a literature procedure. ${ }^{5}$ With 3 in hand, the preparations of $\mathbf{1}$ and $\mathbf{2}$, the key building blocks of Fc-den, were investigated.

It was found that the major obstacle for the successful synthesis of the aldehyde-terminated triferrocenyl derivative $\mathbf{1}$ was not only the possible formation of some oligomers but also a cage compound 8 (Fig. 3b). In other words, one shall control the supramolecular arrangement formed, especially the rotation between Fc's cyclopentadienyl rings of $\mathbf{4}$ during the reaction course, in order to selectively obtain $\mathbf{1}$ instead of $\mathbf{8}$. Although the developed method was facile and chromatography-free (the solid product was filtered and washed off with methanol), numerous attempts had to be made to selectively obtain target compound $\mathbf{1}$ in good yield (Table 1a). In general, better results were found for higher molar excesses of 1,1'diformylferrocene (4) and its higher concentrations; however, the yields did not exceed $32 \%$ (Table 1a, entries 1-4). A breakthrough within this extensive screening of reaction parameters occurred when the reaction was conducted with an excess of $\mathbf{4}$, in its high concentration and in the presence of 9,10-diphenylanthracene as a template (Table 1a, entries 5-7). The basics of template's action were as follows. ${ }^{23 a, b}$ Firstly, from a previous report $^{5}$ it is known that the confined space of cage 8 is too small to incorporate an aromatic molecule (guest), such as 9,10-diphenylanthracene, between stacked 1,3,5-triphenylbenzene moieties. Secondly, the $\pi-\pi$ stacking interaction, a dynamic process, between 9,10-diphenylanthracene and 3 and 1 were expected during the reaction course. For the effective formation of $\mathbf{8}$, the CHO moieties of $\mathbf{4}$ must be in the syn conformation; for the effective synthesis of $\mathbf{8}$, there should be no steric hindrance toward the formation of the stacked cage-type product 8. In other words, the anti-conformation of the substituents in the cyclopendatienyl rings of $\mathbf{4}$ limits the efficient formation of $\mathbf{8}$. Thus, we supposed that a molecule $(9,10-$ diphenylanthracene) that interacts via dynamic $\pi-\pi$ stacking non-covalent interactions with $\mathbf{1}$ or $\mathbf{3}$ (or their intermediate products with 4) might therefore increase this steric hindrance, which results in the inefficient formation of 8 because of facilitation of the discussed anti-conformation of $\mathrm{CHO}$ functionalities. In the light of these facts, this stacking phenomenon with 9,10-diphenylanthracene prevented the formation of cage 8 and enabled the selective synthesis of 1. Importantly, 9,10-diphenylanthracene, and unreacted 3 and $\mathbf{4}$ can be easily removed from the reaction mixture by washing with methanol to yield pure 1 in an excellent yield of 96\% (Table 1a, entry 7). Elemental analysis confirmed the synthesis of pure 1. Finally, to confirm that 1 can interact with 9,10-diphenylanthracene (template) by means of non-covalent forces, at first ${ }^{1} \mathrm{H}$ DOSY NMR analysis was performed (see the ESI $\dagger$ for the data). ${ }^{1} \mathrm{H}$ DOSY NMR is a powerful method to track non-covalent interactions, such as host-guest complexation or $\pi-\pi$ stacking. ${ }^{24 a-c}$ The non-covalent phenomena occurring between two molecules in the sample lead to a change in their diffusion coefficients in ${ }^{1} \mathrm{H}$ DOSY NMR. The diffusion coefficient for 9,10diphenylanthracene in the presence of $1\left(D=7.112 \times 10^{-10} \mathrm{~m}^{2}\right.$ $\mathrm{s}^{-1}$ ) was found to be lower in comparison to the sample of native 9,10-diphenylanthracene in the absence of $1(D=9.621$ $\times 10^{-10} \mathrm{~m}^{2} \mathrm{~s}^{-1}$; see the ESI $\dagger$ for the data). This change was ascribed to the non-covalent $\pi-\pi$ stacking interactions between 1 and 9,10-diphenylanthracene. Although the apparent binding constant $\left(K_{\text {app }}\right)$ was found to be ca. $1.3 \times 10^{2} \mathrm{M}^{-1}$ (because this interaction is a dynamic process) the 9,10-diphenylanthracene:1 system has been clearly detected by cold-spray ESI-MS analysis (see the ESI $\dagger$ for data). This further confirms that 9,10-diphenylanthracene can interact with 1 via noncovalent $\pi-\pi$ stacking interactions and supports the role of 9,10-diphenylanthracene as a template in the synthesis of $\mathbf{1}$.

With this milestone achieved, the synthesis of 2 , a diferrocenyl derivative of $\mathbf{3}$, was investigated (Fig. 3b). The method was based on an acid-catalyzed imine-bond formation reaction between 3 and ferrocenecarboxaldehyde (5). As expected, synthesizing 2 without traces of monoferrocenyl or triferrocenyl triphenylbenzenes has been the biggest challenge. Various reaction parameters were tested (Table 1b). Gratifyingly, the selective and efficient formation of 2 has been achieved by tuning the molar equivalent of $\mathbf{5}$ and its concentration. Similarly to the synthesis of $\mathbf{1}$, pure $\mathbf{2}$ has been obtained in very high yield (90-92\%; Table $1 \mathrm{~b}$, entries 6 and 7) employing an easy-to-perform, chromatography-free method (the solid product was filtered and washed off with methanol). Ultimately, 2 can also be prepared on a gram scale (Table 1b, entry 7). Elemental analysis confirmed the synthesis of pure 2.

All that remained to construct Fc-den was merging 1 and 2. In the light of the successful, facile syntheses of $\mathbf{1}$ and 2, the ultimate goal was to design a facile, chromatography-free methodology to obtain Fc-den. This would make the developed total synthesis chromatography-free in all stages. However, the major issue in this synthetic step was the similar solubility profile for Fc-den to those for $\mathbf{1}$ and 2, i.e. similarly to $\mathbf{1}$ and $\mathbf{2}$, Fc-den is only soluble in chloroalkanes $\left(\mathrm{CH}_{2} \mathrm{Cl}_{2}, \mathrm{CHCl}_{3}\right)$ and THF. Seeking a possible reaction parameter, the reaction in the $\mathrm{THF} / \mathrm{MeOH}$ system was exposed (Fig. 3c; Table 1c). This trial originated from the prediction that $\mathbf{1}$ and $\mathbf{2}$ shall remain dissolved when their THF solution is diluted with $\mathrm{MeOH}$, whilst Fc-den shall precipitate from such a reaction mixture. Through control experiments (Table 1c, entries 1-6), it was indeed found that on the contrary to $\mathbf{1}$ and 2 , Fc-den is not 
a)
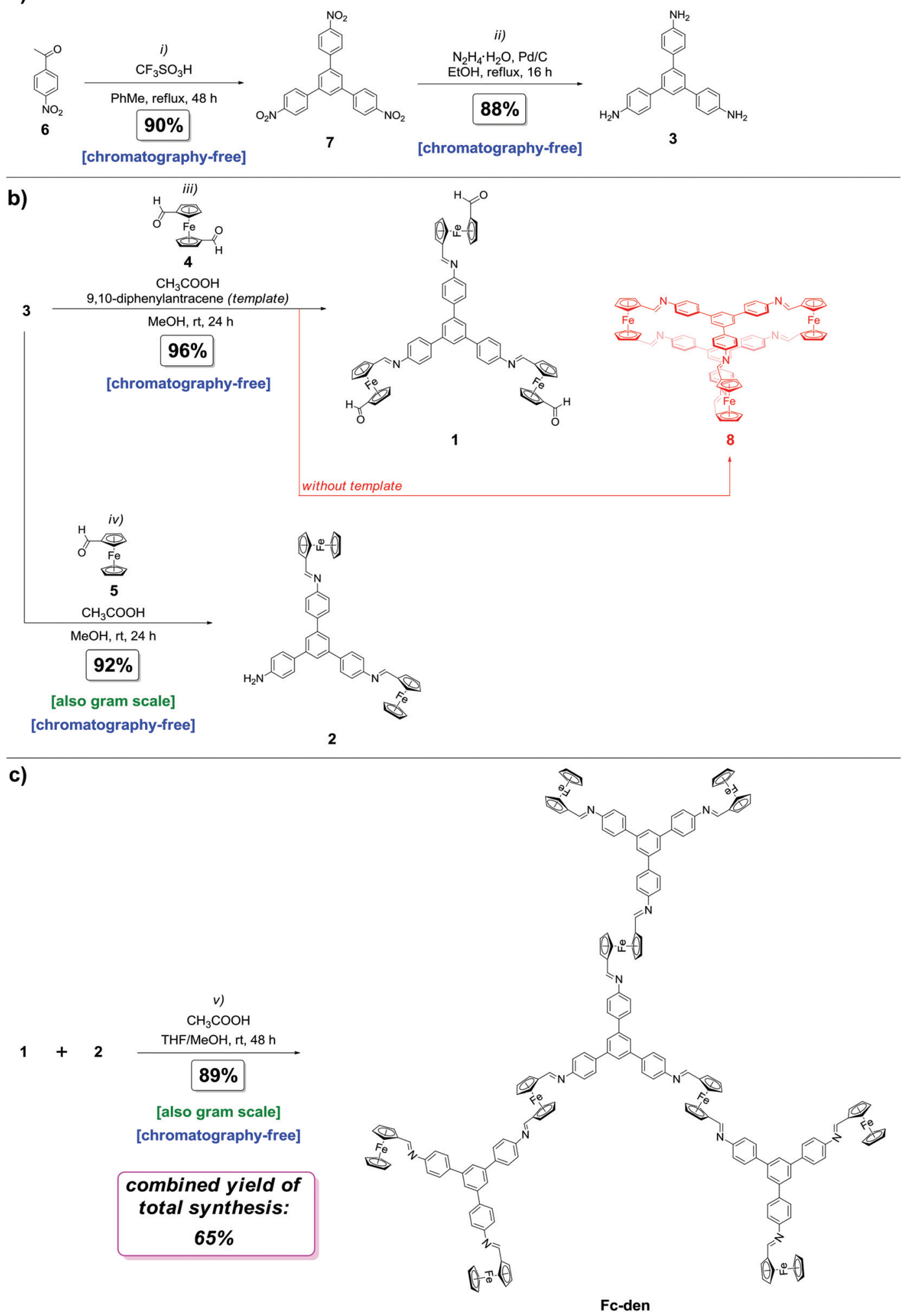

Fig. 3 Total synthesis of Fc-den: (a) synthesis of the starting material 3; (b) synthesis of the key building blocks 1 and 2; (c) assembly of 1 and 2 to obtain Fc-den. Reagents and conditions: (i) 6 (1.0 equiv.), $\mathrm{CF}_{3} \mathrm{SO}_{3} \mathrm{H}$ (cat.), PhMe, reflux, $48 \mathrm{~h}$; (ii) 7 (1.0 equiv.), $\mathrm{N}_{2} \mathrm{H}_{4}$ monohydrate (12.0 equiv.), Pd/C, EtOH, reflux, 16 h; (iii) 3 (1.0 equiv.), 4 (9.0 equiv.), 9,10-diphenylanthracene (4.0 equiv.), $\mathrm{CH}_{3} \mathrm{COOH}$ (cat.), MeOH, rt, 24 h; (iv) 3 (1.0 equiv.), 5 (2.5 equiv.), $\mathrm{CH}_{3} \mathrm{COOH}$ (cat.), $\mathrm{MeOH}, \mathrm{rt}, 24$ h; (v) 1 (1.0 equiv.), 2 (3.3 equiv.), $\mathrm{CH}_{3} \mathrm{COOH}$ (cat.), THF : $\mathrm{MeOH} 1: 1 \mathrm{v} / \mathrm{v}$, rt, $48 \mathrm{~h}$. 
Table 1 Selected optimization of the reaction conditions for the key building blocks 1 (a) and 2 (b) and target Fc-den (c)

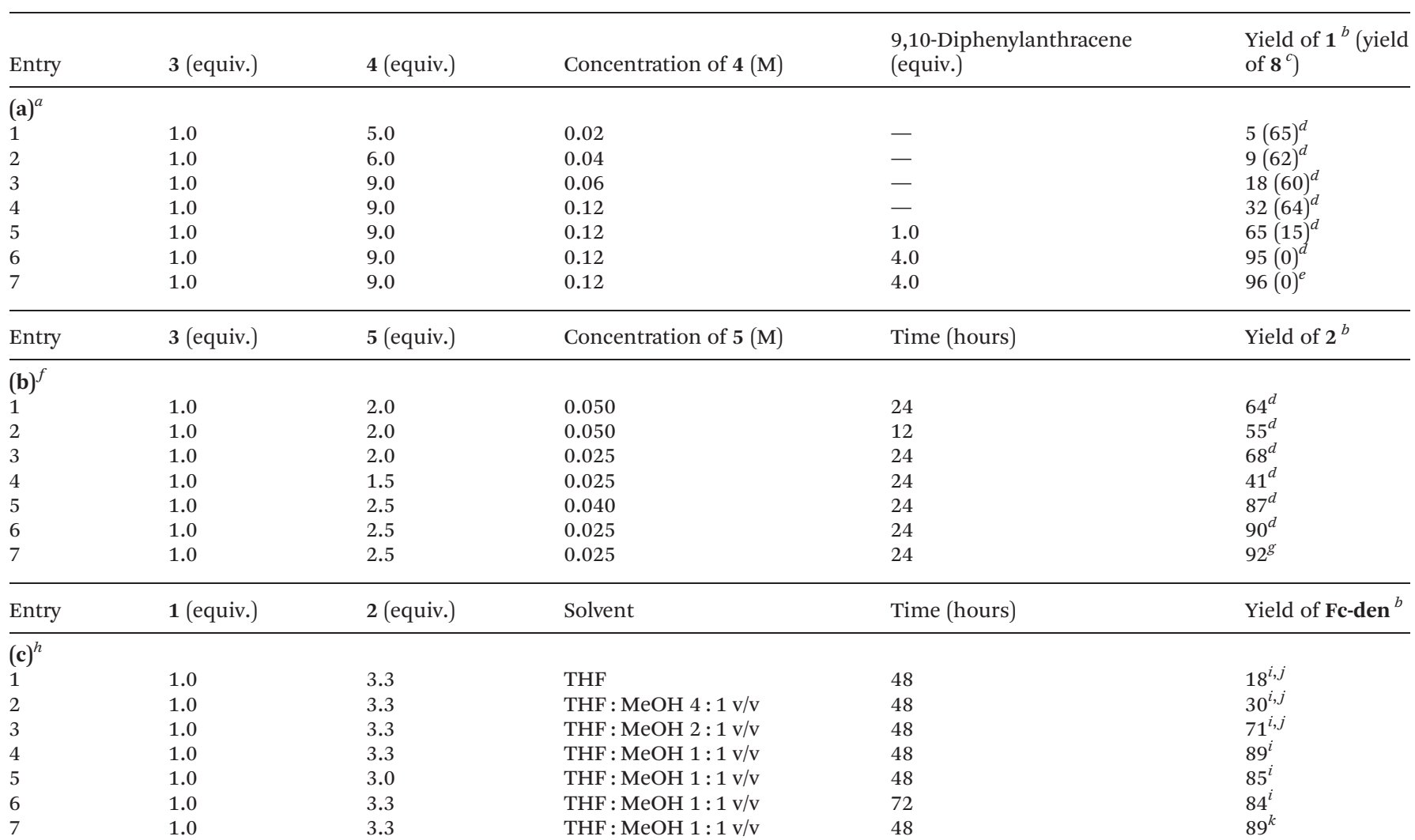

${ }^{a} \mathrm{CH}_{3} \mathrm{COOH}$ (cat.), MeOH, rt, 24 h. ${ }^{b}$ Isolated yields. ${ }^{c}$ Based on ${ }^{1} \mathrm{H}$ NMR. ${ }^{d}$ Reaction scale: $0.02 \mathrm{mmol}$ of $3 .{ }^{e}$ Reaction scale: $0.40 \mathrm{mmol}$ of 3. ${ }^{f} \mathrm{CH}_{3} \mathrm{COOH}$ (cat.), MeOH. ${ }^{g}$ Gram scale reaction (3.00 mmol of 3). ${ }^{h} \mathrm{CH}_{3} \mathrm{COOH}$ (cat.), rt. ${ }^{i}$ Reaction scale: $0.015 \mathrm{mmol}$ of $1 .{ }^{j}$ Impurities of 1 and/or 2 were found in the product (based on ${ }^{1} \mathrm{H}$ NMR). ${ }^{k}$ Gram scale reaction (1.49 mmol of 2 ).

soluble in the THF : MeOH solvent system. Through the application of these conditions, Fc-den has been successfully prepared in a chromatography-free way in an excellent yield of $89 \%$ under mild conditions (Table 1c, entry 4). Importantly, the large-scale access to 2 provided the possibility of the chromatography-free gram-scale preparation of Fc-den (89\%; Table 1c, entry 7). The presence of one set of signals in ${ }^{1} \mathrm{H}$ NMR (12 groups of signals in total; see Fig. S5†) reveals that, in solution, all building subunits of Fc-den, i.e. monosubstituted ferrocenes, 1,1'-disubstituted ferrocenes, terminal 1,3,5triphenylbenzene cores, and imine linkages (two sets), are equivalent on the NMR timescale. The selective formation of one system has been further confirmed by ${ }^{1} \mathrm{H}$ DOSY NMR analysis (see Fig. S7†). Finally, elemental analysis confirmed that pure Fc-den has been synthesized. It is worth noting that ${ }^{1} \mathrm{H}$ NMR analyses revealed that Fc-den is stable in air (the solid sample was kept for three months in air and the ${ }^{1} \mathrm{H}$ NMR spectrum was acquired, see Fig. $\mathrm{S19 \dagger} \dagger$ ), as well as in water (see Fig. S20†).

The UV-Vis spectra of $\mathbf{1}, 2$ and Fc-den in $\mathrm{CHCl}_{3}$ are presented in Fig. 4. Fc-den exhibited incomparably higher absorbance values in comparison to the starting reactants $\mathbf{1}$ and $\mathbf{2}$ (see Fig. S15 $\dagger$ ). The spectra featured two major absorption bands at 262-294 $\mathrm{nm}$ and 330-362 $\mathrm{nm}$. The first band was

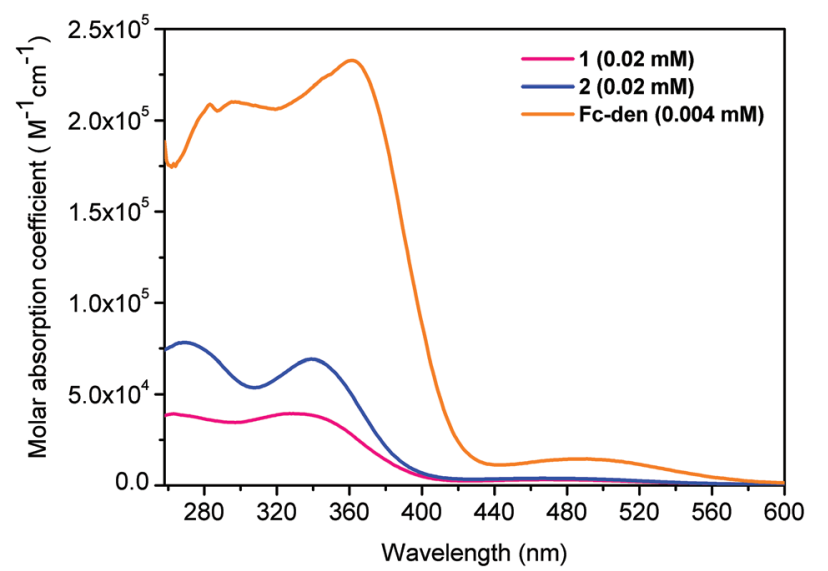

Fig. 4 UV-Vis spectra $\left(\mathrm{CHCl}_{3}\right)$ of 1,2 and Fc-den.

ascribed to the $\pi-\pi^{*}$ transition of 1,3,5-triphenylbenzene cores, whilst the latter originated from the presence of $\mathrm{Fc}$ and imine moieties. The significant red shifts for these bands for Fc-den (294 nm, $362 \mathrm{~nm}$ ) in comparison to the starting materials 1 $(262 \mathrm{~nm}, 330 \mathrm{~nm})$ and $2(266 \mathrm{~nm}, 338 \mathrm{~nm})$ were ascribed to the $\pi$-conjugation within the dendrimer framework. A significantly smaller peak at $488 \mathrm{~nm}$ for Fc-den (observed only for 
this compound) could be attributed to the dynamic $E-Z$ isomerization behavior within imine-type linkages ${ }^{25}$ or some metal-to-triphenylbenzene charge transfers. ${ }^{26}$

$\mathrm{Fc}$ and its derivatives easily undergo one electron oxidation to form a ferrocenium cation in a reversible manner. ${ }^{27-29 a}$ Thus, we investigated the electrochemical behavior of Fc-den in dichloromethane (DCM) by cyclic voltammetry (CV) using a conventional glassy carbon electrode. The cyclic voltammogram of $1 \mathrm{mM}$ Fc-den recorded in DCM with $100 \mathrm{mM}$ tetrabutylammonium hexafluorophosphate (TBAHFP) as a supporting electrolyte for $100 \mathrm{mV} \mathrm{s}^{-1}$ scan rate is presented in the bottom inset of Fig. 5. The recorded voltammogram shows only one pair of current signals. This behavior suggests that the redox (Fc) units of Fc-den are electrochemically equivalent and are oxidized and reduced at the same potential. The number of current signals observed in cyclic voltammograms depends not only on the number of Fc units, but also on the
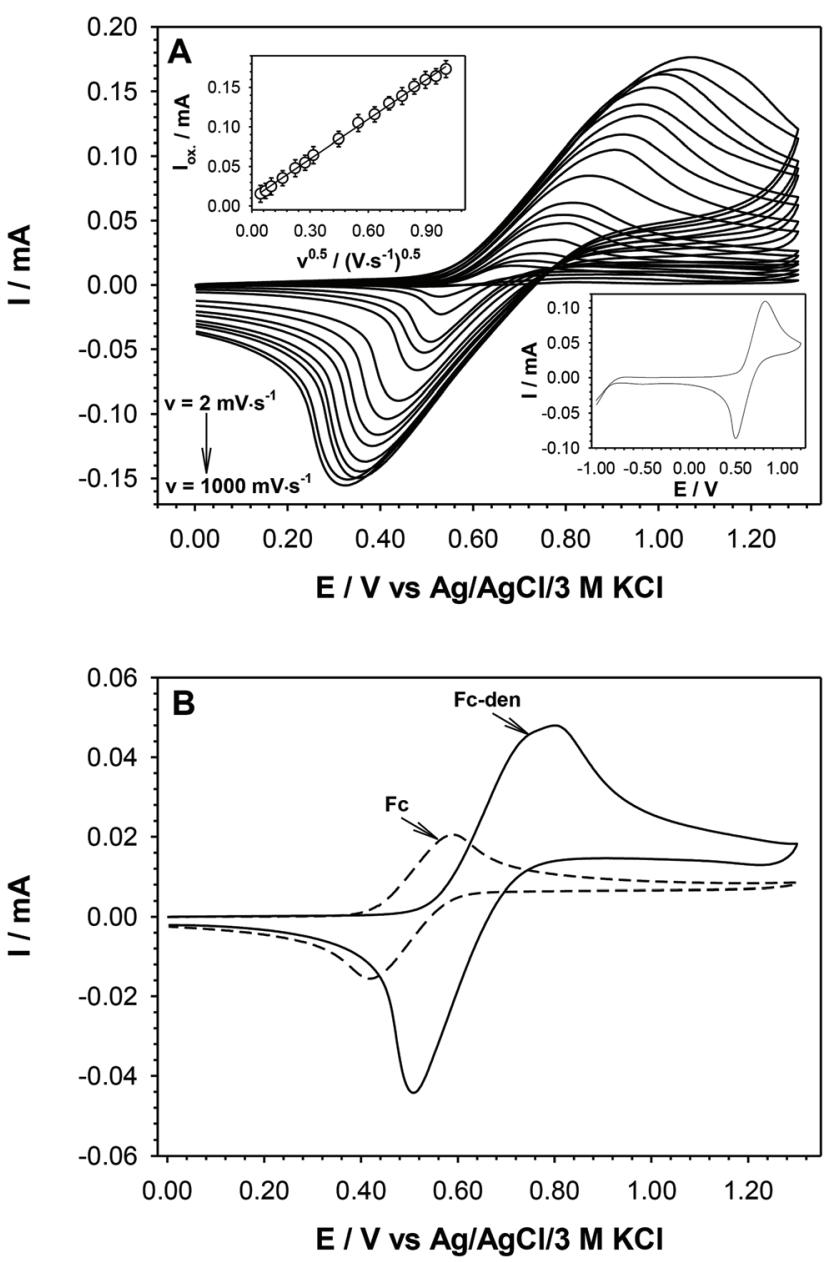

Fig. 5 (A) Cyclic voltammograms of Fc-den recorded in DCM at various scan rates. Top inset: Plot of $\mathrm{Fc}$-den oxidation currents versus the square root of the scan rate. Bottom inset: the CV voltammogram in a wider potential range $\left(v=100 \mathrm{mV} \mathrm{s}^{-1}\right)$. (B) Cyclic voltammograms of Fcden and $\mathrm{Fc}$ recorded in $\mathrm{DCM}$ at $50 \mathrm{mV} \mathrm{s}^{-1}$. Experimental conditions: $C_{\mathrm{Fc}-\text { den }}=1.0 \mathrm{mM}, C_{\mathrm{TBAHFP}}=100 \mathrm{mM}, T=21^{\circ} \mathrm{C}$. distance between them. The closer the $\mathrm{Fc}$ units are to the central benzene core, and therefore closer to each other, the more significant is the electrostatic factor (interaction of the ferrocene cation with the ferrocene cation of the other molecule); therefore multiple CV waves were observed. ${ }^{29 b-e}$ Taking into account the structure of the Fc-den molecule presented in Fig. 3 the distance between Fc-Fc units as well as the Fccentral benzene core is large enough for the electrostatic interactions to not affect the shape and number of current signals. Moreover, the separation of CV signals in the case of compounds with few identical redox centers also depends on the type of electrolyte anions. ${ }^{29 b-e}$ The anions strongly bonded to ferricinium cations such as $\mathrm{PF}_{6}{ }^{-}$or $\mathrm{BF}_{4}{ }^{-}$reduce the ability of CV current signal separation, as well as slow down the electron exchange process. Fc-den contains two types of Fc units in the structure (inner and peripheral one). The presence of two types of redox centres should be visible on the CV curve in the form of two pairs of currents signals, but it only occurs when the Fc-Fc distance is very short. Probably in the case of Fcden, only one type of Fc unit undergoes an electron exchange reaction with the electrode surface. This hypothesis was confirmed by the comparison of the charge values under cathodic or anodic peaks obtained for Fc-den and pure Fc. This ratio $\left(Q_{\text {Fc-den }}: Q_{\mathrm{Fc}}\right)$ is $2: 1$. Moreover, the difference in the position of anodic and cathodic peaks $\left(\Delta E_{\mathrm{p}}\right)$ is $350 \mathrm{mV}$; the value was determined for scan rates $\leq 100 \mathrm{mV} \mathrm{s}^{-1}$, which suggests relatively slow electron transfer and solution resistance. It should be stressed that the value of $\Delta E_{\mathrm{p}}$ for Fc under the same conditions is equal to $160 \mathrm{mV}$; in the case of aqueous solution, the $\Delta E_{\mathrm{p}}$ for $\mathrm{Fc}$ and its derivatives in aqueous solutions is roughly equal to $88 \mathrm{mV}$. This significant difference in the separation of the anode and cathode current signals in relation to aqueous solutions is most likely related to the solution resistance.

In order to determine the value of the diffusion coefficient of Fc-den, CVs were recorded in an $1 \mathrm{mM}$ solution of Fc-den at different scan rates in the range of $2-1000 \mathrm{mV} \mathrm{s}^{-1}$. The linear dependence of the current signal intensity versus square root of the scan rate (see the top inset in Fig. 5) confirmed the diffusional character of the electrochemical reaction. Therefore, from the slope of the plot $I_{\mathrm{pa}}=f\left(v^{0.5}\right)$, the diffusion coefficient for the studied ferrocene derivative according to the Randles-Sevcik equation was determined and was equal to $1.31 \times 10^{-9} \mathrm{~cm}^{2} \cdot \mathrm{s}^{-1}$. In turn, from the intercept of the dependence $\ln \left(I_{\mathrm{pa}}\right)=f\left(E_{\mathrm{pa}}-E_{\mathrm{f}}\right)$, the electron-transfer rate constant $\left(k_{0}=3.01 \times 10^{-4} \mathrm{~cm} \mathrm{~s}^{-1}\right)$ was determined according to the formula:

$$
I_{\mathrm{pa}}=0.227 n F a C_{0}^{*} k_{\mathrm{o}} \exp \left[-\frac{\alpha n F}{R T}\left(E_{\mathrm{pa}}-E_{\mathrm{f}}\right)\right]
$$

where $I_{\mathrm{pa}}$ is the current intensity of the anodic peak, $n$ is the number of electron exchange during the electrode process, $F$ is the Faraday constant, $A$ is the electrode surface area, $C_{0}^{*}$ is the concentration of the electroactive species, $E_{\mathrm{pa}}$ is the potential of the anodic peak, $E_{\mathrm{f}}$ is the formal potential, $R$ is the 
gas constant, $T$ is temperature, and $\alpha$ is the transition coefficient.

The $\mathrm{Fc}$ units were attached to the 1,3,5-triphenylbenzene skeletons via imine bonds. It is known that by applying too high a potential $>1.1 \mathrm{~V}$ such bonds can be broken relatively easily, as representatively shown in our previous report on Fcfunctionalized 1,3,5-triphenylbenzene. ${ }^{30}$ However, in the case of this compound, the decomposition of the imine bond was not observed even when the applied potential was higher than $1.3 \mathrm{~V}$.

Due to the presence of phenyl rings in the Fc-den structure, this compound can be an excellent receptor for other aromatic compounds. The ability of Fc-den in the detection of aromatic compounds was checked electrochemically. To form a recognition layer, the glassy carbon electrode surface was modified by placing a $10 \mu \mathrm{L}$ droplet of $1 \mathrm{mM}$ Fc-den in DCM with addition of $100 \mathrm{mM}$ TBAHFP and $5 \%$ Nafion ${ }^{\circledR}$ and left to dry in a desiccator. Before the voltammetric experiments, the recognition layer was first cycled between 0 and $1 \mathrm{~V}$ in an $100 \mathrm{mM}$ aqueous solution of tetrabutylammonium perchlorate (TBAP) until a stable voltammogram was obtained. In order to prove the analytical potential of the proposed compound, the measurements were carried out using the following aromatic compounds: 1,4-terphenyl, pyrene, phenanthrene, fluorene and 9,10-diphenylanthracene (9,10-DPA). In the presence of $200 \mu \mathrm{M}$ analyte in the solution, a drastic decrease in the intensity of the Fc-den oxidation signal was observed only in the case of 9,10-DPA (Fig. 6). In the case of the other compounds, the registered changes in the intensity of the Fc-den current signal were insignificant. This high sensitivity and selectivity of Fc-den to 9,10-DPA are probably due to the steric fit; it is possible to form a complex by $\pi-\pi$ interactions.

Having known the above discussed specificity and inspired by the fact that 9,10-diphenylantracene can be used as a template during the synthesis steps of Fc-den (Fig. 3b), we began

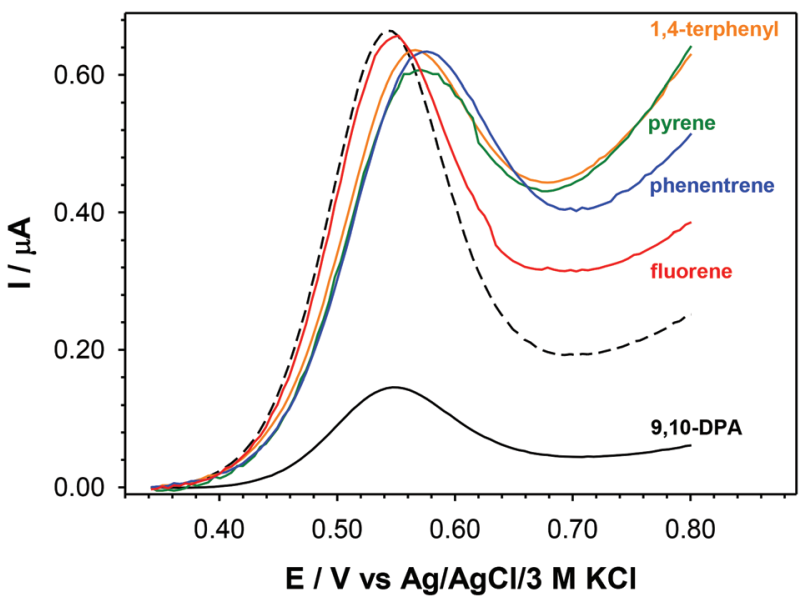

Fig. 6 DPV voltammograms of GC/Fc-den-TBAHFP-Nafion® recorded in the presence of various aromatic analytes in an aqueous solution of $100 \mathrm{mM}$ TBAP. $C_{\text {analyte }}=200 \mu \mathrm{M}$. The dotted line stands for the spectrum of native Fc-den. to engineer the application of Fc-den as the building unit of an analytical device dedicated to the specific recognition of 9,10-DPA, a polycyclic aromatic hydrocarbon (PAH) commonly used in, e.g. the technologies of organic light emitting diodes. $^{31,32}$ The analytical characteristics of the sensor (GC/Fcden-TBAHFP-Nafion $\left.{ }^{\circledR}\right)$, which has been fabricated as noted above, were determined electrochemically on the basis of the changes in the Fc-den oxidation current signal. The representative differential pulse voltammograms (DPV) plotted as a function of the 9,10-DPA concentration are presented in Fig. 7. After the addition of 9,10-DPA to the solution, a decrease in the intensity of the Fc-den current signal was observed. This decrease was greater when a greater concentration of the analysed compound was introduced into the solution. The signal stabilization after the addition of 9,10-DPA took place after three consecutive voltammograms were recorded in succession (total time: 4 minutes). The detection limit (LOD) was estimated from the calibration plot as the three standard deviations of the five independent controls (measurements of the current in the pure buffer solution). The regression equations describing the linear responses of $I_{\text {Fc-den }}=f\left(C_{9,10-\text { DPA }}\right)$ as well as the analytical ranges and LODs are presented in Table 2A, while the calculated inter- and intraday precisions are given in Table 2B.

A great advantage of the proposed sensor is that 9,10-DPA did not form too stable complexes with Fc-den, so the receptor layers did not require regeneration. It was enough to immerse the sensor (GC/Fc-den-TBAHFP-Nafion $®$ ) after the measurement in a pure $100 \mathrm{mM}$ TBAP aqueous solution, and the sensor was ready for re-use, which is a very important factor from the viewpoint of the application of the designed methodology. It should be also stressed that analytical studies were performed in an aqueous environment with small addition of DCM (not higher than 3\%). Finally, it is worth noting that no significant interaction between the parent subunit structure of

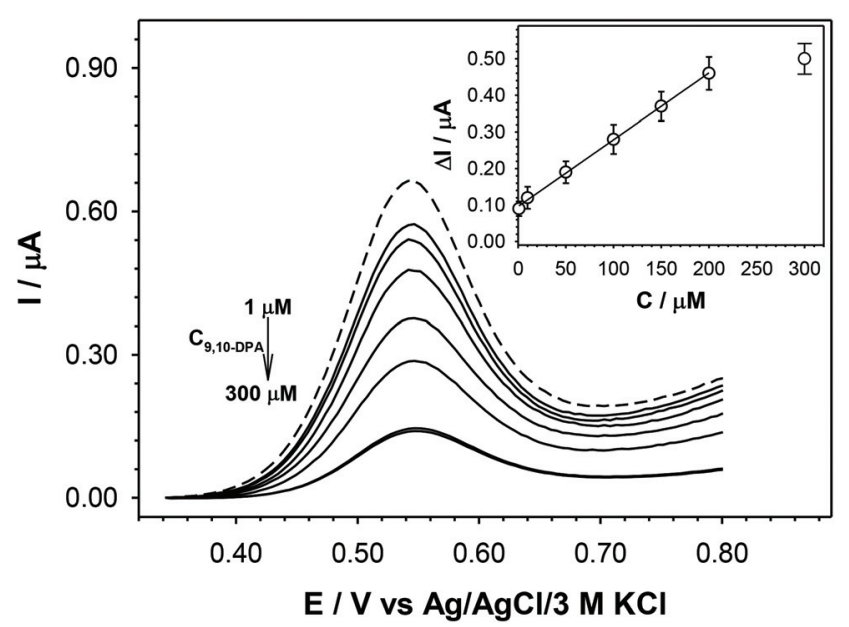

Fig. 7 DPV voltammograms of a receptor (GC/Fc-denTBAHFP-Nafion $\circledast$ ) recorded at various concentrations of 9,10-DPA in an aqueous solution of 100 mM TBAP. Inset: Calibration plots. 
Table 2 (A) Calibration equation obtained in aqueous solution and (B) recovery results

\begin{tabular}{|c|c|c|c|c|c|}
\hline \multicolumn{2}{|l|}{ Regression equation } & $R^{2}$ & Analytical range $[\mu \mathrm{M}]$ & $\operatorname{LOD}[\mu \mathrm{M}]$ & $\operatorname{RSD}(\%)$ \\
\hline \multicolumn{6}{|c|}{ A: Calibration equation obtained in an aqueous solution of $100 \mathrm{mM}$ TBAP $(n=3)$} \\
\hline \multicolumn{2}{|c|}{$I=(1.83 \pm 0.03) \cdot 10-{ }^{3} C_{9,10 \mathrm{DPA}}+(0.096 \pm 0.003)$} & 0.9995 & $0.1-200$ & 0.06 & 4.5 \\
\hline 9,10-DPA added $[\mu \mathrm{M}]$ & 9,10-DPA & & RSD (\%) intraday & RSD (\%) interday & Recovery (\%) \\
\hline \multicolumn{6}{|c|}{ B: Recovery results of TBAP solution spiked by $9,1-\mathrm{DPA}(n=3)$} \\
\hline 5.00 & 4.90 & & 3.3 & 5.2 & 98 \\
\hline 50.0 & 50.5 & & 4.2 & 5.0 & 99 \\
\hline 100 & 101 & & 4.8 & 4.9 & 99 \\
\hline
\end{tabular}

Fc-den, i.e., 1 without formyl functionalities, which was recently reported by our group, ${ }^{30}$ was observed during the electrochemical assays. This means that the organized, $\pi$-conjugated structure of Fc-den is indeed essential for providing the studied electrochemical recognition ability.

\section{Conclusions}

In conclusion, herein it is shown that the $\pi$-conjugated ferrocene-containing dendrimer (Fc-den) can be successfully prepared employing facile, efficient, chromatography-free processes that proceed under mild conditions. Noteworthily, the presented total synthesis can be regarded as time-, solventand cost-saving since there is no need for chromatographic purification at each synthetic step. While the imine-bond formation reaction has been demonstrated to be a convenient way for the synthesis of many valuable $\pi$-conjugated molecules, the presented total synthesis provides important tools for chromatography-free methods in total synthesis as well as for controlling the dynamic covalent chemistry behaviours with ferrocene-tethered systems. Electrochemical studies with Fc-den revealed one pair of ferrocenes' current signals. Ultimately, the title dendrimer has been employed for the construction of an electrochemical sensor dedicated to the recognition of 9,10-diphenylanthracene. The limit of detection value equalled $0.06 \mu \mathrm{M}$, and importantly receptor layers consisting of Fc-den did not require regeneration. Taking into account the easiness of the preparation of the target dendrimer under mild conditions, the possibility of its gram-scale synthesis, as well as its property to recognize selected aromatic species and to track this process under electrochemical conditions, it is believed that this work would open up new avenues in the chemistry of ferrocene-bearing molecules. Our future work in this topic will include, e.g. the preparation of further generations of Fc-den and new Fc-den-derived highly ordered molecules, as well as the evaluation of their properties and applications.

\section{Conflicts of interest}

There are no conflicts to declare.

\section{Acknowledgements}

Financial support from Warsaw University of Technology (WUT) is acknowledged. This work was implemented as a part of Operational Project Knowledge Education Development 2014-2020 co-financed by the European Social Fund, project no. POWR.03.02.00-00-I007/16-00 (POWER 2014-2020). We would like to thank Dr Magdalena Poplawska (WUT) for fruitful discussions and for sharing her knowledge in organic synthesis over the years of our scientific collaboration.

\section{Notes and references}

1 D. Astruc, Eur. J. Inorg. Chem., 2017, 6-29.

2 K. Heinze and H. Lang, Organometallics, 2013, 32, 56235625.

3 S. Daum, V. F. Chekhun, I. N. Todor, N. Y. Lukianova, Y. V. Shvets, L. Sellner, K. Putzker, J. Lewis, T. Zenz, I. A. M. de Graaf, G. M. M. Groothuis, A. Casini, O. Zozulia, F. Hampel and A. Mokhir, J. Med. Chem., 2015, 58, 20152024.

4 M. Nakahata, Y. Takashima, H. Yamaguchi and A. Harada, Nat. Commun., 2011, 2, 511.

5 A. Kasprzak and P. A. Guńka, Dalton Trans., 2020, 49, 69746979.

6 T. Romero, A. Caballero, A. Tarraga and P. Molina, Org. Lett., 2009, 11, 3466-3469.

7 M. S. Inkpen, S. Scheerer, M. Linseis, A. J. P. White, R. F. Winter, T. Albrecht and N. J. Long, Nat. Chem., 2016, 8, 825-830.

8 L. E. Wilson, C. Hassenrgck, R. F. Winter, A. J. P. White, T. Albrecht and N. J. Long, Angew. Chem., Int. Ed., 2017, 56, 6838-6842.

9 E. Abbasi, S. F. Aval, A. Akbarzadeh, M. Milani, H. T. Nasrabani, S. W. Joo, Y. Hanifehpour, K. NejatiKoshki and R. Pashaei-Asl, Nanoscale Res. Lett., 2014, 9, 247.

10 (a) K. Ariga, H. Ito, J. P. Hill and H. Tsukube, Chem. Soc. Rev., 2012, 41, 5800-5835; (b) W.-J. Li, W. Wang, X.-Q. Wang, M. Li, Y. Ke, R. Yao, J. Wen, G.-Q. Yin, B. Jiang, X. Li, P. Yin and H.-B. Yang, J. Am. Chem. Soc., 2020, 142, 
8473-8482; (c) B. Jiang, L.-J. Chen, Y. Zhang, H.-W. Tan, L. Xu and H.-B. Yang, Chin. Chem. Lett., 2016, 27, 607-612.

11 S. Nlate, J. Ruiz, J.-C. Blais and D. Astruc, Chem. Commun., 2000, 417-418.

12 B. Alonso, I. Cuadrado, M. Moran and J. Losada, J. Chem. Soc., Chem. Commun., 1994, 2575-2576.

13 (a) C.-O. Turrin, E. Manoury and A.-M. Caminade, Molecules, 2020, 25, 447; (b) C. Ornelas, J. R. Aranzaes, E. Cloutet, S. Alves and D. Astruc, Angew. Chem., Int. Ed., 2007, 46, 872-877; (c) J. Camponovo, J. Ruiz, E. Cloutet and D. Astruc, Chem. - Eur. J., 2009, 15, 2990-3002.

14 (a) S. Sengupta and S. K. Sadhukhan, Organometallics, 2001, 20, 1889-1891; (b) E. S. Serkova, A. A. Chamkin, K. L. Boldyrev and Z. B. Shifrina, Macromolecules, 2020, 53, 2735-2743.

15 B. J. Ravoo, Dalton Trans., 2008, 1533-1537.

16 (a) C. M. Cardona and A. E. Kaifer, J. Am. Chem. Soc., 1998, 120, 4023-4024; (b) L. Wang, L.-J. Chen, J.-Q. Ma, C.-H. Wang, H. Tan, J. Huang, F. Xiao and L. Xu, J. Organomet. Chem., 2016, 823, 1-7; (c) M.-C. Daniel, J. Ruiz and D. Astruc, J. Am. Chem. Soc., 2003, 125, 11501151; (d) Q.-J. Li, G.-Z. Zhao, L.-J. Chen, H. Tan, C.-H. Wang, D.-X. Wang, D. A. Lehman, D. C. Muddiman and H.-B. Yang, Organometallics, 2012, 31, 7241-7247; (e) Q. Han, Q.-J. Li, J. He, B. Hu, H. Tan, Z. Abliz, C.-H. Wang, Y. Yu and H.-B. Yang, J. Org. Chem., 2011, 76, 9660-9669; (f) G.-Z. Zhao, L.-J. Chen, C.-H. Wang, H.-B. Yang, K. Ghosh, Y.-R. Zheng, M. M. Lyndon, D. C. Muddiman and P. J. Stang, Organometallics, 2010, 29, 6137-6140.

17 A. Salmon and P. Jutzi, J. Organomet. Chem., 2001, 637-639, 595-608.

18 (a) L. Xu, Y.-X. Wang, L.-J. Chen and H.-B. Yang, Chem. Soc. Rev., 2015, 44, 2148-2167; (b) S. Ø. Scottwell and J. D. Crowley, Chem. Commun., 2016, 52, 2451-2464; (c) E. Perris, Coord. Chem. Rev., 2004, 248, 279-297; (d) L. Xu, L.-J. Chen and H.-B. Yang, Chem. Commun., 2014, 50, 5156-5170; (e) G.-Y. Wu, L.-J. Chen, L. Xu, X.-L. Zhao and H.-B. Yang, Coord. Chem. Rev., 2018, 369, 39-75; (f) M. Saito, H. Shinokubo and H. Sakurai, Mater. Chem. Front., 2018, 2, 635-661; $(g)$ W. Wang, L.-J. Chen, X.-Q. Wang, B. Sun, X. Li, Y. Zhang, J. Shi, Y. Yu, L. Zhang, M. Liu and H.-B. Yang, Proc. Natl. Acad. Sci. U. S. A., 2015, 112, 5597-5601; (h) D. Astruc, C. Ornelas and J. Ruiz, Acc. Chem. Res., 2008, 41, 841-856.

19 (a) C. Schubert, J. T. Margraf, T. Clark and D. M. Guldi, Chem. Soc. Rev., 2015, 44, 988-998; (b) C.-O. Turrin, J. Chiffre, D. de Montauzon, J.-C. Daran, A.-M. Caminade,
E. Manoury, G. Balavoine and J.-P. Majoral, Macromolecules, 2000, 33, 7328-7336; (c) C.-O. Turrin, J. Chiffre, J.-C. Daran, D. de Montauzon, G. Balavoine, É. Manoury, A.-M. Caminade and J.-P. Majoral, C. R. Chim., 2002, 5, 309-318.

20 E. David, K. Thirumoorthy and N. Palanisami, Appl. Organomet. Chem., 2018, 32, e4522.

21 (a) D. Kaleeswaran, P. Vishnoi and R. Murugavel, J. Mater. Chem. C, 2015, 3, 7159-7171; (b) J. Palomero, J. A. Mata, F. Gonzalez and E. Peris, New J. Chem., 2002, 26, 291-297.

22 E. G. Percastegui, J. Mosquera, T. K. Ronson, A. J. Plajer, M. Kieffer and J. R. Nitschke, Chem. Sci., 2019, 10, 20062018.

23 (a) Templated Organic Synthesis, ed. F. Diederich and P. J. Stang, WILEY-VCH Verlag GmbH, Weinhein, Germany, 2007, ISBN: 978-3-527-61352-6; (b) Y. Xu, R. Kaur, B. Wang, M. B. Minameyer, S. Gsanger, B. Meyer, T. Drewello, D. M. Guldi and M. von Delius, J. Am. Chem. Soc., 2018, 140, 13413-13420.

24 (a) Y. Cohen, L. Avram and L. Frish, Angew. Chem., Int. Ed., 2005, 44, 520-554; (b) F. Parenti, F. Tassinari, E. Libertini, M. Lanzi and A. Mucci, ACS Omega, 2017, 2, 5775-5784; (c) L. Avram and Y. Cohen, J. Org. Chem., 2002, 67, 26392644.

25 T. Berbasova, E. M. Santos, M. Nosrati, C. Vasileiou, J. H. Geiger and B. Borhan, ChemBioChem, 2016, 17, 407414.

26 A. J. King, Y. V. Zatsikha, T. Blessener, F. Dalbec, P. C. Goff, M. Kayser, D. A. Blank, Y. P. Kovtun and V. N. Nemykin, J. Organomet. Chem., 2019, 887, 86-97.

27 P. Molina, A. Tárraga, D. Curiel and M. D. Velasco, J. Organomet. Chem., 2001, 637-639, 258-265.

28 T. Yamaguchi, K. Takahashi and T. Komura, Electrochim. Acta, 2001, 46, 2527-2535.

29 (a) M. Vilas-Boas, E. M. Pereira, C. Freire and A. R. Hillman, J. Electroanal. Chem., 2002, 538, 47; (b) R. J. LeSuer and W. E. Geiger, Angew. Chem., Int. Ed., 2000, 39, 248-250; (c) F. Barrière, N. Camine and W. E. Geiger, J. Am. Chem. Soc., 2002, 124, 7262-7263; (d) F. Barrière and W. E. Geiger, J. Am. Chem. Soc., 2006, 128, 3980-3989; (e) F. Barrière and W. E. Geiger, Acc. Chem. Res., 2010, 43, 1030-1039.

30 A. Kasprzak, P. A. Guńka, A. Kowalczyk and A. M. Nowicka, Dalton Trans., 2020, 49, 14807-14814.

31 S. B. Lee, S. N. Park, C. Kim, H. W. Lee, H. W. Lee, Y. K. Kim and S. S. Yoon, Synth. Met., 2015, 203, 174-179.

32 H. Chen, W. Liang, Y. Chen, G. Tian, Q. Dong, J. Huang and J. Su, RSC Adv., 2015, 5, 70211-70219. 